\title{
Multiple Shots Averaging in Laser Flash Measurement ${ }^{\dagger}$
}

\author{
Giovanni Ferrarini $^{1, *}$, Alessandro Bortolin ${ }^{1}$, Gianluca Cadelano ${ }^{2}$, Lorenzo Finesso ${ }^{3}$ \\ and Paolo Bison ${ }^{1}$ \\ 1 CNR-ITC, C.so Stati Uniti 4, 35127 Padova, Italy; alessandro.bortolin@itc.cnr.it (A.B.); \\ paolo.bison@itc.cnr.it (P.B.) \\ 2 CNR-ISAC, C.so Stati Uniti 4, 35127 Padova, Italy; g.cadelano@isac.cnr.it \\ 3 CNR-IEIIT, via Gradenigo 6/B, 35131 Padova, Italy; lorenzo.finesso@ieiit.cnr.it \\ * Correspondence: giovanni.ferrarini@itc.cnr.it; Tel.: +390498295700 \\ + Presented at the 15th International Workshop on Advanced Infrared Technology and Applications \\ (AITA 2019), Florence, Italy, 17-19 September 2019.
}

Published: 23 September 2019

\begin{abstract}
The knowledge of the thermal properties of materials is a key resource for the correct design of industrial components. The laser flash method is a well-known procedure to determine the thermal diffusivity of a wide range of materials. However, in some cases there is the need of limiting the input power, or measuring materials with high thermal capacity, or investigating thick samples. Under these circumstances, the expected signal-to-noise ratio can reach extremely low values. To solve this issue, the existing laser flash apparatus has been improved, creating a new control and data acquisition system that is able to repeat multiple times the emission of the laser impulse and the measurement of the thermal response of the specimen. This gives the possibility of averaging several measurements, leading to a decrease of the noise. The experimental validation on different samples shows the feasibility of the proposed setup, that makes it possible to work with low power inputs.
\end{abstract}

Keywords: photothermal phenomena; laser flash; thermal parameters

\section{Introduction}

The nondestructive evaluation of materials is a fundamental tool for the industrial production, as it can significantly contribute to improve the design of the components and to the assessment of the production quality [1,2]. Several methods and techniques are available to analyze material samples and investigate the chemical, structural, or thermal properties [3]. The latter are of great importance, for example during the design phase of a components. The thermal properties are used as input of simulation models [4] and providing accurate data to the models is the basic condition to obtain reliable predictions. A predetermined value of a thermal property could be also the desired requirement of an industrial component. The measurement on a component coming from different production batches could help the manufacturer to identify anomalous products [5]. Broadly speaking, the use of a nondestructive method is a great advantage, especially when dealing with real-size mockups [6] or when performing on-site evaluations [7].

Amongst all available methods for determining the thermal properties [8], one of the most popular is the Laser Flash Method (LFM) [9]. The LFM is a procedure where a heat flux is applied on the front face of a specimen and the temperature is measured on the back of the specimen [10-12]. The LFM is typically applied to small size disk-shaped specimens in order to measure their thermal diffusivity $(\alpha$ value). The main advantages of this method are simplicity, rapidity of measurement, and the possibility to measure the thermal diffusivity on a wide range of materials also within a wide temperature range. The LFM is chosen also because it gives the possibility of obtaining the thermal conductivity, if a 
procedure with adequate reference samples is used or if other thermal properties are measured. In the second case the knowledge of the density $(\rho)$, that could be measured through the Archimedes principle, and of the specific heat $\left(C_{p}\right)$, that could be obtained through differential scanning calorimetry (DSC), makes it possible to calculate the thermal conductivity as the product of the density, the specific heat, and the thermal diffusivity [13].

The original LFM method has been widely studied and applied, expecially for the characterization of thermal barrier coatings (TBC) [14-17]. Several modifications has been proposed, both from the mathematical [18] and from the experimental standpoint [19] to improve the results. One critical issue is limiting the input power, that for some ranges of thermal properties and thickness of the specimen may lead to an unwanted and nonuniform overheating [16]. Vozàr and Hohenauer [20] proposed to divide the energy of a single laser pulse across smaller repeated pulses, obtaining results comparable to the traditional technique. Recently, Ruffio et al. [21] explored the use of an high speed laser pulse train in order to improve the signal-to-noise ratio. This study proposes a novel experimental setup that allows the automatic repetition of single pulses with a user defined time delay between each pulse. This leads to an increase of the signal-to-noise ratio.

\section{References}

1. Shepard, S.M.; Hou, J.; Lhota, J.R.; Golden, J.M. Automated processing of thermographic derivatives for quality assurance. Opt. Eng. 2007, 46, 051008-051008-6.

2. Cielo, P.; Lewak, R.; Balageas, D.L. Thermal Sensing For Industrial Quality Control. In Thermosense VIII: Thermal Infrared Sensing for Diagnostics and Control; Kaplan, H., Ed.; SPIE: Bellingham, WA, USA, 1986; pp. 47-54.

3. Achenbach, J.D. Quantitative nondestructive evaluation. Int. J. Solids Struct. 2000, 37, 13-27.

4. Bortolin, A.; Bison, P.; Cadelano, G.; Ferrarini, G.; Fortuna, S. Measurement of thermophysical properties coupled with LCA assessment for the optimization of a historical building retrofit. J. Phys. Conf. Ser. 2015, 655, 012011.

5. Ferrarini, G.; Bison, P.; Bortolin, A.; Cadelano, G.; Rossi, S. Thermal diffusivity measurement of ring specimens by infrared thermography. In Thermosense: Thermal Infrared Applications Xxxix; Bison, P., Burleigh, D., Eds.; SPIE: Bellingham, WA, USA, 2017. doi:10.1117/12.2262512.

6. Ferrarini, G.; Bison, P.; Bortolin, A.; Cadelano, G. Thermal response measurement of building insulating materials by infrared thermography. Energy Build. 2016, 133, 559-564.

7. Cadelano, G.; Bison, P.; Bortolin, A.; Ferrarini, G.; Peron, F.; Girotto, M.; Volinia, M. Monitoring of historical frescoes by timed infrared imaging analysis. Opto-Electron. Rev. 2015, 23, 102-108.

8. Jannot, Y.; Degiovanni, A. Thermal Properties Measurement of Materials; Wiley-ISTE: London, UK, 2018.

9. ASTM E1461-13. Standard Test Method for Thermal Diffusivity by the Flash Method; ASTM International: West Conshohocken, PA, USA, 2013.

10. Parker, W.J.; Jenkins, R.J.; Butler, C.P.; Abbott, G.L. Flash Method of Determining Thermal Diffusivity, Heat Capacity, and Thermal Conductivity. J. Appl. Phys. 1961, 32, 1679-1684.

11. Bison, P.G.; Marinetti, S.; Mazzoldi, A.; Grinzato, E.; Bressan, C. Cross-comparison of thermal diffusivity measurements by thermal methods. Infrared Phys. Technol. 2002, 43, 127-132.

12. Philippi, I.; Batsale, J.C.; Maillet, D.; Degiovanni, A. Measurement of thermal diffusivities through processing of infrared images. Rev. Sci. Instrum. 1995, 66, 182-192.

13. Bison, P.; Bortolin, A.; Cadelano, G.; Ferrarini, G.; Grinzato, E. Comparison of some thermographic techniques applied to thermal properties characterization of porous materials. In Proceedings of 11th International Conference on Quantitative Infrared Thermography-QIRT2012, Naples, Italy, 11-14 June 2012. doi:10.21611/qirt.2012.364.

14. Cernuschi, F.; Golosnoy, I.O.; Bison, P.; Moscatelli, A.; Vassen, R.; Bossmann, H.-P.; Capelli, S. Microstructural characterization of porous thermal barrier coatings by IR gas porosimetry and sintering forecasts. Acta Mater. 2013, 61, 248-262. 
15. Cernuschi, F.; Bison, P.; Mack, D.E.; Merlini, M.; Boldrini, S.; Marchionna, S.; Capelli, S.; Concari, S.; Famengo, A.; Moscatelli, A.; et al. Thermo-physical properties of as deposited and aged thermal barrier coatings (TBC) for gas turbines: State-of-the art and advanced TBCs. J. Eur. Ceram. Soc. 2018, 38, 3945-3961.

16. Cernuschi, F.; Bison, P. The influence of the laser energy on the thermal diffusivity evaluation of TBC by laser flash. J. Therm. Spray Tech. 2008, 17, 465-472.

17. Taylor, R.E. Thermal conductivity determinations of thermal barrier coatings. Mater. Sci. Eng. A 1998, 245, 160-167.

18. Blumm, J.; Opfermann, J. Improvement of the mathematical modeling of flash measurements. High Temperatures-High Pressures 2002, 34, 515-521.

19. Baba, T.; Ono, A. Improvement of the laser flash method to reduce uncertainty in thermal diffusivity measurements. Meas. Sci. Technol. 2001, 12, 2046.

20. Vozár, L.; Hohenauer, W. Measurement of the thermal diffusivity by the laser-flash method with repeated pulses. High Temperatures-High Pressures 2001, 33, 9-16.

21. Ruffio, E.; Pradere, C.; Sommier, A.; Batsale, J.-C.; Kusiak, A.; Battaglia, J.-L. Signal noise ratio improvement technique for bulk thermal diffusivity measurement. Int. J. Therm. Sci. 2018, 129, 385-395.

(C) 2019 by the authors. Licensee MDPI, Basel, Switzerland. This article is an open access article distributed under the terms and conditions of the Creative Commons Attribution (CC BY) license (http:/ / creativecommons.org/licenses/by/4.0/). 